Estuarine, Coastal and Shelf Science (1997) 44, 685-702

\title{
Modelling Thermohaline Properties in an Estuarine Upwelling Ecosystem (Ría de Vigo: NW Spain) Using Box-Jenkins Transfer Function Models
}

\author{
E. Nogueira, F. F. Pérez and A. F. Ríos \\ Instituto de Investigacións Mariñas, C.S.I.C., Eduardo Cabello, 6. 36208 Vigo, Spain
}

Since 1987, twice weekly, hydrological variables have been monitored at a fixed station in the Ría de Vigo (NW Spain), aiming to examine the time scales of variability and the relationships to meteorological conditions. The present paper analyses: (1) the advantage of Box-Jenkins transfer function (TF) models (single output-multiple input), a type of linear stochastic model, to describe the dynamic behaviour of the system; and (2) the coupling between the Ría and meteorological events at the time scale of autonomy of this coastal inlet affected by the Iberian coastal upwelling, approximately a fortnightly period. In order to achieve these objectives, thermohaline properties have been used to characterize the estuarine ecosystem (output variables), while wind regime, runoff in the drainage basin and incoming solar radiation have been considered as the main forcing variables (input variables). The use of the amplitude time series, derived from principal component analysis (PCA) applied to the deseasonalized meteorological variables, is also explored as a different set of input variables.

When compared with standard regression models, all TF models built to describe thermohaline behaviour had reduced residual variance. Similar TF models, as well as percentage of explained variance, were also obtained when meteorological variables or the amplitude time series were used as input variables. The fitted TF models provided an insight into the 'inertial' behaviour of the system and the time scales of coupling of the system with the forcing variables. The plausible physical mechanisms which link the response of the system with the observed meteorological variability are also discussed. As could be expected, bottom thermohaline properties show a stronger inertial behaviour than the surface ones, which is particularly marked for bottom temperature. Besides, the shelf 
domain, by means of upwelling-downwelling events, strongly influences surface and bottom temperature, as well as bottom salinity; by contrast, surface salinity is mainly influenced by the effect of wind along the main axis of the Ría and runoff. In relation to the time scales of coupling between the system and the forcing variables, thermohaline properties show a dependance with the meteorological conditions in, at least, the immediately preceding fortnight period. It was concluded that: (1) TF models that incorporate meteorological information described the dynamic behaviour of the system adequately; and (2) this type of model can be useful as a first approximation to develop more sophisticated (deterministic) models, since, with the purpose of modelling any state variable of the system, both the coupling between different domains and the time scales of the interactions must be taken into account.

Keywords: thermohaline properties; meteorological forcing; time series; transfer functions models; Ría de Vigo; Iberian upwelling

\section{Introduction}

Characterizing dynamic systems may be undertaken following several different methods (Schindler, 1987). Time-series analysis (Box \& Jenkins, 1976), one of these methods, has been a successfully applied technique in diverse ecological fields to explore the dynamic behaviour of such systems (Poole, 1976; Mendelssohn, 1981; Keller, 1987). The models developed by time-series analysis have several characteristics: (1) they are stochastic; (2) they employ only measurable variables and estimable parameters; and (3) they are conceptually simple and intuitively appealing. Several interesting properties of the fluctuations of the analysed variable can be deduced by examining the probabilistic properties of the model fitted to the data.

Traditional methods of time-series analysis are mainly concerned with decomposing the variation in a series into trend, seasonal variation, other cyclic changes and the remaining 'irregular' fluctuations. A previous paper, established the deterministic components (e.g. seasonal cycles and the long-term variation) of the hydrological and meteorological time 
series resulting from a sampling programme that has been carried out in the Ría de Vigo since February 1987 (Nogueira et al., 1997). The present paper processes the 'irregular' fluctuations; that is, once the seasonal and trend components of the time series have been removed.

An important concept which must be considered when dealing with ecological time-series analysis is the functional autonomy of the ecosystem under study. The functional autonomy of an ecological domain depends on the size of the domain and the average time over which autonomy is tested (Lewis \& Platt, 1982). For a particular domain, some characteristic time scale will exist at which functional autonomy breaks down; averaging over this characteristic period (or longer) will allow elucidation of coupling between the ecological domain and the external forcing factors. For estuarine systems, the residence time is one measure of time scale of functional autonomy; advection must largely control biogeochemical processes in such estuaries where residence time is short, but the processes of internal cycling may dominate where long residence time occurs (Pilson, 1985).

In order to investigate the relationships between the estuarine system dynamics and external forcing factors, linear stochastic transfer function (TF) models (Box \& Jenkins, 1976; Jenkins, 1979; Tiao \& Box, 1981) have been used to describe the evolution of conservative variables (thermohaline properties) related to those of several meteorological factors. Both output and input variables were fortnightly averaged according to the mean residence time of the Ría de Vigo, estimated using the Box-model approach (Ríos, 1992), and to the typical forcing period by atmospheric fluctuations on the Galician coast (McClain et al., 1986; Alvarez-Salgado et al., 1993). For comparative purposes, TF models were compared with standard multiple regression models by means of the residual variance and the coefficient of determination $\left(r^{2}\right)$; in all cases, the TF models provided the best fit to the data.

\section{Materials and methods}

Analysis 
A time series is a collection of observations ordered in time and shaped by both deterministic and stochastic events. Thus, if it is assumed that an observable time series, $Y_{t}$, follows an additive model:

$$
Y_{t}=S S C_{t}+T_{t}+R\left[Y_{t}\right]
$$

where $t$ is the index for time, $S S C_{t}$ is the seasonal component, $T_{t}$ is the trend component, and $R\left[Y_{t}\right]$ is the remaining irregular fluctuation (Peña, 1992). This approach is particularly valuable when the variation is dominated by seasonality and/or trend (Chatfield, 1992). To analyse the relationships among variables with a seasonal component, it is necessary to remove the seasonal fluctuations from the data. Otherwise, correlations of variables that have regular seasonal fluctuations would simply reflect the correspondence or lack of correspondence of their seasonality. Likewise, it was necessary to remove trends in variables before correlations were tested. Therefore, the present data have been deseasonalized by subtracting the seasonal value for the fortnight of the year in question from the corresponding fortnightly measurements. The data have also been detrended by means of the rates of long-term change (Hirsch et al., 1982; van Belle \& Hughes, 1984; Nogueira et al., 1997). Once deterministic components have been removed, the resulting time series [deseasonalized and detrended time series, $\left(R\left[Y_{t}\right)\right]$ fluctuate around a mean with constant variance (stationary series), and the random process that generated the time series can be mathematically defined by using the Box- Jenkins approach (Jenkins, 1979; Chatfield, 1992). In the present paper, the use of transfer function models for modelling $R\left[Y_{t}\right]$ time series of thermohaline properties is explored.

Univariate ARIMA (autoregressive integrated moving average) models (single output) represent a response time series $\left(R\left[Y_{t}\right]\right)$ as a linear combination of its own past values (i.e. an autoregressive component) and current and past values of the error term (i.e. a moving average component). Transfer function models (single output-multiple input) incorporate not only the past history of the output variable $\left(R\left[Y_{t}\right]\right)$, but also the current and past history of other related input variables $\left(R\left[X_{I t}\right], \ldots, R\left[X_{i t}\right]\right)$. Whereas univariate models can often result in an empirical understanding of the underlying mechanisms generating the series, TF models can be used not only for forecasting but also for gaining an increased 
understanding of the behaviour of the system. Thus, according to the TF model's approach, an output time series $R\left[Y_{t}\right]$ may be split into two components:

$$
R\left[Y_{t}\right]=R\left[Y_{t}\right]^{*}+N_{t}
$$

where $R\left[Y_{t}\right]^{*}$ contains that part of $R\left[Y_{t}\right]$ which can be explained in terms of other related input variables, $R\left[X_{i t}\right]$, and $N_{t}$ is an error or noise term which can not be explained in terms of $R\left[X_{i t}\right]$.

When dealing with TF models, some assumptions must be taken into account:

(1) the series, when suitably arranged, possesses a unidirectional causation relationship (i.e. no feedback);

(2) the input-output relationship is time invariant;

(3) the input-output relationship is linear, thus:

$$
R\left[Y_{t}\right]^{*}=\Sigma \omega_{i}(B) R\left[X_{i t}\right]
$$

where $B$ is the backshift operator $B^{k} R\left[X_{t}\right]=R\left[X_{t-k}\right] ; R\left[X_{i t}\right]$ is the deseasonalized and detrended $i$ th input term; and $\omega_{i}(B)$ is the transfer function's weight for the $i$ th input series; and

(4) $N_{t}$, the noise term, contains the effect of other relevant input variables excluded by the model and, analogous to the univariate model, it may be decomposed, so that:

$$
N_{t}=f_{t}+a_{t}
$$

where $f_{t}$ is the predictable part of $N_{t}$ and $a_{t}$ is a set of independent, identical and normally distributed random shocks (or white noise) with zero mean and constant variance $\sigma_{a}^{2}$.

By using a expanded notation, and assuming that the noise term could be described in terms of an autoregressive component, the TF model may be written as follows:

$$
Y_{t}=S S C_{t}+T_{t}+\Sigma \omega_{i}(B) X_{i t}+\Phi(B) N_{t}+a_{t}
$$

where $\Phi(B)$ is an autoregressive (AR) polynomial oforder $p$ [i.e. $\Phi(B) N_{t}$ is the predictable part, $f_{t}$, of thenoise term] and the other terms in Equation (5) have been defined above.

Fitting the model to the observed data involved three steps: process identification, estimation of the parameters and diagnostic checking. The first step involved determining how many and which terms in Equation (5) should be retained in the final models. 
Univariate ARIMA models were initially first constructed for the dependent (output) and independent (input) variables for three reasons (Jenkins, 1979):

(1) so that any reduction in residual variance, $\sigma_{a}$, a measure of goodness of fit, as a result of introducing the input variables could be measured;

(2) to provide a first approximation to the structure of the noise model to be used in the TF model; and

(3) to filter both the input and output series before calculating their cross-correlation function $(\mathrm{CCF})$ at all lags, a process termed pre-whitening. Pre whitening is necessary because the data may be serially correlated, that is, measurements were correlated with preceding measurements. Testing for correlation between sets of serially correlated data would result in an exaggerated impression of statistical power since the sequential data are not independent measurements. It would be 'pseudoreplication' in time (Jordan et al., 1991).

In the second step, the parameters that best fit the data were estimated simultaneously. The steps of model building involved the examination of the autocorrelation (ACF) and partial autocorrelation (PACF) functions of the stationary time series, and the pre whitened CCFs between the input, $R\left[X_{i t}\right]$, and output, $R\left[Y_{i t}\right]$, time series. The ACF measured the (linear) Pearson correlation between neighbouring points in a series; the PACF measured the strength of the relationship between time periods in a series when dependence on intervening periods was removed or 'partialled out'. The ACF and PACF are used to determine the class of stochastic process generating the series (i.e. autoregressive (AR), moving average (MA) or autoregressive-moving average (ARMA)] as well as the order(s) of this process(es) (Jenkins, 1979; Peña, 1992). The pre-whitened CCFs provided evidence for a relationship between the input and output series at any lag.

Finally, diagnostic checking involved removal of non-significant components from the model and testing the residuals $\left(a_{t}\right)$ for departure from white noise; this was done by means of:

(1) a plot of the residuals with 'control limits' $\pm 2 \sigma_{a}$, which can indicate points where the residual seem to be unrepresentative when compared with the overall distribution of 
residuals. Such unrepresentative or abnormal residuals are indicative of large external shocks;

(2) the residual ACF looks for evidence of non-randomness in the residuals, which could be indicative of inadequacies in the TF model and the noise model; and

(3) the CCF between the residuals and the input series provides evidence of inadequacy in the TF model. If the residuals were not equivalent with white noise, a new model was identified and the process of model building repeated (Jenkins, 1979; Peña \& Arnáiz, 1981).

Study site

The Rías Baixas (NW Iberian Peninsula) are four flooded tectonic valleys that behave as partially mixed estuaries (Beer, 1983) with a two-layered positive residual circulation pattern (Fraga, 1981). The density-driven flow (gravitational convection) is strongly influenced by the freshwater contribution, the wind regime along the main axis of the Ría and the upwelling-downwelling events (Blanton et al., 1987; Prego \& Fraga, 1992; Rosón et al., 1997), control the water exchange between the rías and the shelf. The Ría de Vigo (Figure 1), the southernmost of the Rías Baixas is $\sim 160 \mathrm{~km}^{2}$ in area, $\sim 3 \cdot 3 \mathrm{~km}^{3}$ in capacity and averages $\sim 21 \mathrm{~m}$ depth with a maximum depth of $\sim 45 \mathrm{~m}$ in the main channel. It is connected with the Atlantic Ocean by means of two mouths; the Northern mouth $(\sim 2 \cdot 5 \mathrm{~km}$ wide and $\sim 23 \mathrm{~m}$ average depth) and the Southern mouth (about twice as wide as the Northern mouth and deeper) (Ríos, 1992). The main axis, following an ENE-WSW orientation from head to mouth, is $\sim 30 \mathrm{~km}$ in length. The mean tidal range is $\sim 3 \mathrm{~m}$ and the River Verdugo, the main freshwater tributary, has a mean annual flow of $\sim 13 \mathrm{~m}^{3} \mathrm{~s}^{-1}$. The drainage basin is $\sim 590 \mathrm{~km}^{2}$ in area (Ríos et al., 1992).

\section{Data}

Since 1987, the Instituto de Investigacións Mariñas has kept a fixed station in the Ría de Vigo (Stn E3, Figure 1). It is located in the main channel and in the middle zone $\left(42^{\circ} 14.5^{\prime} \mathrm{N}, 8^{\circ} 45.8^{\prime} \mathrm{W}\right)$ of the Ría; hydrographic samples are taken twice weekly at depths 
of 1 and $40 \mathrm{~m}$ with 51 PVC Niskin bottles provided with Watanabe rotating thermometer frames. Due to the location (Figueiras et al., 1994) and sampling interval (Taylor \& Howes, 1994), when data are averaged over an appropriate time scale (Lewis \& Platt, 1982), Stn E3 is suitable for evaluating the response of the system due to changes in the external forcing factors.

According to the criterion of functional autonomy, to explore the linkage between meteorological events and the dynamic response of the Ría de Vigo, the data to be analysed are time series of 144 fortnightly averaged values of meteorological variables and thermohaline properties. In Table 1, the data processing applied to the rough time series and the reduction in variance associated with this data management are shown (Nogueira et al., 1997). The time series analysis is applied to the deseasonalized and detrended time series, i.e. seasonal anomalies time series. According to Chatfield (1992), neither the $R\left[Y_{i t}\right]$ nor the $R\left[X_{i t}\right]$ time series were transformed since: (1) the transformed variables have no direct physical interpretation; and (2) there is little improvement in description or forecast performance of the system when a transformation of variables is applied.

Thermohaline properties (output data). Conservative properties are suitable variables to evaluate the coupling between the Ría and the external factors. Temperature was recorded from Watanabe thermometers. Salinity was calculated from the equation proposed in UNESCO (1983), and conductivity measurements were made with an inductive salinometer Autosal 8400A calibrated with 'Standard Water'.

Meteorological variables (input data). Since the responsible mechanism of the system dynamic response is direct water replacement due to estuarine residual circulation, mainly influenced by the upwelling- downwelling events, the wind regime along the main axis of the Ría and the freshwater contribution (Rosón et al., 1995), the Ekamn transport components, $q x$ and $q y$, the runoV in the drainage basin up to Stn E3 $\left(\sim 480 \mathrm{~km}^{2}\right), Q r$, and the incoming solar radiation, $Q s$, have been used here to characterize the external meteorological conditions. 
The Ekman transport components were supplied by the Instituto Español de Oceanografía (Vigo); they were obtained from geostrophic wind calculations (Bakun, 1973) for a point located at $43^{\circ} \mathrm{N} 11^{\circ} \mathrm{W}$, which represents an upwelling index reference point where the index is assumed to be the same as all of the west coast of Galicia (Blanton et al., 1987). The cross-shore, $q x$, and the along-shore, $q y$, components have been rotated $20^{\circ}$ anti- clockwise, so that they result, respectively, perpendicular and parallel to the Galician Rías Baixas coastline (and at the same time, respectively, parallel and perpendicular to the main axis of the Ría de Vigo). Since, for co-ordinate axes, a right-handed system has been used, negative values of the cross-shore component indicate upwelling (i.e. northerly wind). Due to the lack of data of representative wind conditions inside the Ría over the analysed period, and as this 'local' wind blows predominantly, due to orographic effects, following the main axis of the Ría (Chase, 1975), the along-shore component of the Ekman transport has been considered as a rough approximation to the wind conditions inside the Ría. Positive values of the along-shore component, $q y$, are associated with easterly wind.

The runoff, $Q r$, was estimated as a function of precipitation by using the equation given by Ríos et al. (1992). The precipitation values monitored at the meteorological station in Peinador airport, located $10 \mathrm{~km}$ away from Stn E3 and at $200 \mathrm{~m}$ above sea level, have been used in the present study. The incoming solar radiation, $Q s$, was estimated by Mosby's formula (Dietrich et al., 1980), fitted as a function of Julian day and the degree of cloudness (in eighths of sky coverage) according to Rosón et al. (1995).

The meteorological time series that has been used and subsequently processed (Table 1), is the result of averaging the daily meteorological values for each meteorological variable between the day of hydrographic sampling of Stn E3 and the three previous days. The reason for taking this average interval is based on the inertia of coastal circulation to the atmospheric pressure fluctuations (McClain et al., 1986; Aulvarez-Salgado et al., 1993), and of the time scale of transient activity typical of a mid-latitude west wind regime, characterized by the so-called synoptic frequency band (3-5 days) of the energetic cyclonic activity (Lenhart et al., 1995). Following this procedure, the meteorological time series will have the same length as the original hydrographic time series (i.e. two data per week) and 
may be managed in the same manner. Besides, it is worth noting that a set of input variables have been used as the seasonal anomalies of the meteorological time series [Figure 2(a,b)].

Principal components derived from meteorological variables (input data). Principal component analysis (PCA) is used to replace the original variables by a smaller number of new variables, a linear combination of the original variables, that capture most of the total original variance but are uncorrelated with each other. The new variables are principal components (PCs), and they are arranged in descending order according to the amount of the original variance they reproduce (Legendre \& Legendre, 1983). In the present paper, PCA has been applied to the seasonal anomalies of the meteorological time series, which results in an uncorrelated series for each mode (PC), the amplitude time score [Figure 2(ce)], which expresses the relative importance of each mode over time (Jassby \& Powell, 1990); once these PCs have been interpreted, it would be possible to define some meteorological 'scenarios'. The resultant three first components (Table 2) retain $\sim 90 \%$ of the original variance. The PC1, which retains about $50 \%$ of the original variance, defines the characteristic mid-latitude west wind regime; positive values of PC1 are significantly related to westerly winds (or south-westerly) associated with high runoff and low irradiance. PC2 is indicative of long-shore winds, thus relating with upwellingdownwelling events. Jointly, PC1 and PC2 retain about $75 \%$ of the original variance. They represent the dominant meteorological features in the western Galician coast. PC3 defines irradiance conditions associated with the wind regime and runoff; positive values correspond with south-easterly winds, low runoff and irradiance. Finally, PC4 relates crossshore winds and runoff; positive values of PC4 occur with easterly wind and anomalous high runoff. PC3 and PC4 are associated with transitional periods between the dominant meteorological features

\section{Results}

Univariate ARIMA models were first constructed for the input (meteorological, $R\left[q x_{t}\right]$, $R\left[q y_{t}\right], R\left[Q r_{t}\right]$ and $R\left[Q s_{t}\right]$, as well as PCs, as a different set) and output (surface and bottom 
thermohaline properties) variables. The univariate models for the input and output variables were used to calculate pre-whitened CCFs between the input and output variables. The $\mathrm{ACF}$ and PACF for all of the input variables reveal that no pre-whitening was required to remove the internal structure. The results for salinity and temperature time series are exposed separately.

\section{Surface and bottom salinity $\left(\mathrm{R}\left[\mathrm{Ss}_{\mathrm{t}}\right]\right.$ and $\left.\mathrm{R}\left[\mathrm{Sb}_{\mathrm{t}}\right]\right)$}

The damped sinusoidal decay pattern of the ACF for bottom salinity, $R\left[S b_{t}\right]$, [Figure 3(a)] is indicative of a stationary autoregressive model. The PACF had significant values at lags 1 and 23 [Figure 3(b)], indicating that $R\left[S b_{t}\right]$ may be described by a first-order autoregressive model with a seasonal component. The ACF and PACF for surface salinity, $R\left[S s_{t}\right]$, exhibited a similar pattern, although the seasonal component may be obviated due to its low significance level. To remove autocorrelation, both output series were prewhitened by fitting the univariate models (Tables 3 and 4). The pre-whitened output series were then used to calculate the pre-whitened CCFs with the input time series.

The CCFs of pre-whitened surface salinity with the seasonal anomalies of both along-shore Ekman transport (cross-shore winds), $R\left[q y_{t}\right]$, and runoff, $R\left[Q r_{t}\right]$, showed significant values at lags 0 and 1 , and at lag 0 , respectively.

The possibility remains that the relationship between pre-whitened surface salinity and cross-shore wind regime is not distinct from the one between pre-whitened surface salinity and runoff. That is, one of the relationships may be only an artifact of the association between precipitation and cross-shore winds (Table 2); thus, both relationships may represent the same phenomenon. In order to examine this possibility, adjusted variable plots (Goldman et al., 1989) were constructed to clarify the relationships between pre-whitened surface salinity and each of these input variables. In an adjusted variable plot of two given variables, the effects of any additional factors are first removed from each variable by linear regression, and the residuals are plotted against each other. The partial correlation coefficient, $r_{p}$, between the two variables is the correlation between these two sets of 
residuals. In order to ensure that these associations are not trivial (i.e. determined by one or a few exceptional points) the data outside $95 \%$ prediction interval $(\sim \pm 2 \mathrm{SE}$ of the regression) were removed (black dots in Figure 4), and the association was recalculated.

The adjusted variable plot of pre-whitened surface salinity and cross- shore winds, both adjusted for runoff, illustrates a clear direct relationship $\left(r_{p}=0 \cdot 57, P<0 \cdot 001\right)$ independent of runoff [Figure 4(a)]. Similarly, the adjusted variable plot of pre-whitened surface salinity and runoff, both adjusted for cross-shore winds, exhibits an inverse association $\left(r_{p}=-0 \cdot 36\right.$, $P<0 \cdot 001)$ [Figure 4(b)]. Therefore, cross-shore winds and runoff represent two separate factors affecting surface salinity.

According to these findings, the TF model for surface salinity (Table 3) must include both $R\left[q y_{t}\right]$ and $R\left[Q r_{t}\right]$ input variables. Since these two input variables are not independent variables (Table 2), this fact must be taken into account when building the two-input TF model (Peña, 1992). Therefore, it is necessary to adjust the combined effect between the two-input-related variables. The followed procedure can be summarized as follows:

(1) to build the TF model for one of the input variables, for instance, $\left(R\left[Y_{t}=\omega_{1}(B) R\left[X_{1 t}\right]\right.\right.$ $\left.+N_{t}\right)$;

(2) to build the TF model between the input variables $\left(R\left[X_{2 t}=\omega_{21}(B) R\left[X_{1 t}\right]+N_{t}^{*}\right)\right.$;

(3) the noise term, $N t^{*}$, was used to estimate the TF model for $N_{t}\left(N_{t}=\omega_{3}(B) N_{t}^{*}+A_{t}\right)$; and

(4) a global TF model was developed by combining the prior results $R\left[Y_{t}\right]=\omega_{1}(B) R\left[X_{1 t}\right]$ $\left.+\omega_{3}(B)\left\{R\left[X_{2 t}\right]-\omega_{21}(B) R\left[X_{1 t}\right]\right\} \mathrm{u}+A_{t}\right)$.

An advantage when using the amplitude time score series derived from PCA as input variables is that PCs are uncorrelated (orthogonal) variables and, therefore, it is not necessary to apply the adjusted procedure described above. The CCFs between prewhitened surface salinity and PC1 (positive values: westerlies or south-westerlies, high runoff and low irradiance) and PC3 (positive values: easterlies and low irradiance) showed significant values at lags 0 and 1 , and at lag 0 , respectively. These results agree with those obtained when meteorological variables were used as input variables. 
Table 3 shows the resultant univariate and TF models developed for surface salinity; for comparative purposes, the multiple regression model provided by using a standard multiple regression method is also included. The analysis of the residuals of the TF models did not show model inadequacies. The graphic representation of the model which best fitted the surface salinity evolution (denoted by an arrow in Table 3) is shown in Figure 5.

The different stochastic models constructed for bottom salinity time series are shown in Table 4. The multiple regression model suggests that two input variables, $R\left[q x_{t}\right]$ and $R\left[q y_{t}\right]$, must be included in the TF models for $R\left[S b_{t}\right]$. The CCFs of pre-whitened bottom salinity with the seasonal anomalies of both cross-shore Ekman transport (upwelling-downwelling events), $R\left[q x_{t}\right]$, and along-shore Ekman transport (a rough estimation of wind regime along the main axis of the Ría), $R\left[q y_{t}\right]$, showed significant values from lags 0 and 1 , and at lag 0 , respectively. No adjustment was required between these input variables, since they are uncorrelated variables (Table 2). Thus, the TF model which best fitted the $R\left[S b_{t}\right]$ time series (Table 4 and Figure 6) includes the effects of the two components of the wind regime. Subsequent analysis of the residuals showed that the model was not overspecified regarding $R\left[q x_{t}\right]$.

The results obtained when PCs were used as input variables are slightly different: the CCF of pre-whitened bottom salinity with both PC1 and PC2 [along-shore component of the wind; negative values: northerly winds (i.e. upwelling events)] showed significant values at lags 0 and 1, respectively. The observed differences between the TF models built to describe the bottom salinity evolution by means of single meteorological variables or PCs are due to the definition of the latter as a linear combination of the former. Thus, the results obtained when PCs are used as input variables do not contravene those obtained with the meteorological variables.

Surface and bottom temperature $\left(\mathrm{R}\left[\mathrm{ts}_{\mathrm{t}}\right]\right.$ and $\left.\mathrm{R}\left[\mathrm{tb}_{\mathrm{t}}\right]\right)$

The ACF for $R\left[t s_{t}\right]$ and $R\left[t b_{t}\right]$ exhibited a damped sinusoidal decay, which is indicative of a stationary autoregressive model. However, the PACF for $R\left[t_{t}\right]$ showed a significant value 
at lag 1, suggesting a first-order autoregressive model, while that for $R\left[t b_{t}\right]$ presented two significant values, at lags 1 and 2, which indicates a second-order autoregressive model; thus, for bottom temperature, the univariate model suggested that the current fortnight value depends on the past two fortnight values.

The TF for surface temperature (Table 5) incorporates only the cross-shore Ekman's transport component as an input variable. The CCF between pre-whitened $R\left[t_{t}\right]$ and $R\left[q x_{t}\right]$ presented two significant values at lags 0 and 1 . The result obtained when PCs were used as input variables seems rather different. The CCFs showed that pre-whitened surface temperature is significant correlated with PC2 at lag 0 and with PC1 at lag 1 . When meteorological variables were used as input variables, pre-whitened surface temperature is a function solely of the alongshore wind regime, in the present and in the preceding fortnight. However, when PCs are used as input variables, pre-whitened surface temperature depends on the along-shore wind regime in the present fortnight, and on the dominant component of the meteorological variability, the cross-shore wind regime, in the preceding fortnight. The multiple TF model which best fitted $R\left[t_{t}\right]$ is shown in Figure 7 .

In a first approximation, the multiple regression model for $R\left[t b_{t}\right]$ suggested that only $R\left[q x_{t}\right]$ must be included as an input variable in the TF model. However, the CCFs between the pre-whitened $R\left[t b_{t}\right]$ and $R\left[q x_{t}\right], R\left[q y_{t}\right]$ and $R\left[Q r_{t}\right]$ showed significant values at lags 0 and 1 for $R\left[q x_{t}\right]$, and at lag 0 for $R\left[q y_{t}\right]$ and $R\left[Q r_{t}\right]$. The adjusted variable plots (not showed) clarified that cross-shore winds and runoff represent the same phenomenon affecting bottom temperature evolution; therefore, $R\left[q y_{t}\right]$ and $R\left[q x_{t}\right]$ were used as input variables to develop TF models for $R\left[t b_{t}\right]$ (Table 6). Similar TF models were constructed using PCs as input variables. The CCFs between pre-whitened $R\left[t b_{t}\right]$ and PC1 and PC2 showed significant correlation values at lag 0 and at lags 0 and 1 , respectively. The multiple TF model which best fitted $R\left[t b_{t}\right]$ is shown in Figure 8 .

\section{Discussion}

Surface and bottom salinity $\left(\mathrm{R}_{[} \mathrm{Ss}_{\mathrm{t}}\right]$ and $\left.\mathrm{R}\left[\mathrm{Sb}_{\mathrm{t}}\right]\right)$ 
The univariate models revealed that it would be difficult to describe the fortnightlyaveraged evolution of salinity based on its own past values alone; for surface and bottom, the univariate model explained, respectively, 12 and $16 \%$ of the variation of the deseasonalized and detrended time series (Tables 3 and 4). In a previous paper (Nogueira et al., 1997), it was established that salinity shows high-frequency variation. In fact, the fortnightly-averaged time series which has been used here retains $\sim 65$ and $\sim 55 \%$ of the variance of the original, once purged and filled up, surface and bottom salinity time series (Table 1). The high-frequency variation of salinity explains the scarce description capability of the univariate models at this time scale.

The situation differs when meteorological events are considered as input variables. The multiple regression model explains $\sim 48 \%$ of the variation of the deseasonalized and detrended surface salinity evolution, $R\left[S s_{t}\right]$; this percentage falls, $\sim 26 \%$, for the $R\left[S b_{t}\right]$ time series. In both cases, multiple TF models accounted for the higher percentage of explained variance; $\sim 60$ and $\sim 41 \%$, respectively (Tables 3 and 4 ).

The $R\left[S s_{t}\right]$ evolution could be described in terms of the deseasonalized cross-shore winds and runoff time series (Table 3). These two factors are associated; the deseasonalized runoff values could be described in terms of the estimated deseasonalized cross-shore winds in the present and in the preceding fortnight $(R[Q r]=-(12( \pm 1)+5( \pm 1) B] \cdot(R[q y]$, $\left.r^{2}=0 \cdot 38, P<0 \cdot 001\right)$. However, they represent two different processes affecting surface salinity (Figure 4). The freshwater input [i.e. higher runoff values than those which correspond with the respective fortnight mean of the seasonal cycle $\left.\left(R\left[Q r_{t}\right]>0\right)\right]$, tend to lower surface salinity. By contrast, positive values of deseasonalized cross-shore winds, $R\left[q y_{t}\right]>0$, mainly caused by increased easterly winds conditions, tend to raise surface salinity. Increased runoff, generally associated with westerly winds, acts as a dilution factor, while easterly winds, generally associated with dry weather conditions, operate, through several distinct physical mechanisms, as a mixing factor. Anomalous high funnelled easterly winds (Chase, 1975), could lead to the formation of waves having major mixing efficiency than the oceanic waves, of longer period, associated to westerly wind 
conditions (Beer, 1983; Pond \& Pickard, 1986). Another plausible mechanism that could explain the rise of surface salinity by means of funnelled easterly winds is the reinforcement of the vertical velocity shear, which increases the eddy frictional stress and thus enhances mixing between layers (Pond \& Pickard, 1986). Besides, as geostrophic conditions are unlikely to occur in the Ría, funnelled easterly winds may lead to a reinforcement of the surface outflow, thus causing a net seaward transport of surface layer, and hence, by continuity, the entrance of saltier water from below. Conversely, westerly winds, as a local effect, tend to slow down the outflow of the surface layer, thus reducing the velocity shear and diminishing the entrance of water from below the surface layer. The TF models constructed with the amplitude time series derived from PCA support the interpretation given above.

Present fortnightly averaged values of the $R\left[S s_{t}\right]$ time series depend particularly on present fortnightly values of the input time series, and to a lesser degree, on the immediate-past fortnightly values of the cross-shore wind conditions; in relation to this variable, the influence of the preceding fortnightly period represents a considerable percentage, $\sim 60 \%$, of the influence in the present fortnight (Table 3). To quantify the relative contribution of the seasonal anomalies of cross-shore winds and runoff, the step response function can be used, which describes how the output is related to the input of a linear system (Chatfield, 1992). The step response function describes the response of the system to a step change in the input. Assuming that $R\left[q y_{t-i}\right]=0 \mathrm{~m}^{2} \mathrm{~s}^{-1}$ for $i=0$ and 1 , then, a value of $R\left[Q r_{t}\right]=17 \mathrm{~m}^{3} \mathrm{~s}^{-1}$ (which has been chosen in accordance with the standard deviation of the fortnightly averaged time series; Table 1), involves a decrease of surface salinity of $\Delta S s_{t}$ of $\sim-0 \cdot 5$. On the other hand, assuming that $R\left[Q r_{t-i}\right]=0 \mathrm{~m}^{3} \mathrm{~s}^{-1}$ for $i=0$, then a fortnight value of $R\left[q y_{t}\right]=0 \cdot 8$ $\mathrm{m}^{2} \mathrm{~s}^{-1}$ (Table 1), implies a rise in surface salinity of $\Delta S s_{t} \sim 0 \cdot 9$, and of $\Delta S s_{t} \sim 1 \cdot 4$ if $R\left[q y_{t}\right.$ $\left.{ }_{i}\right]=0.8 \mathrm{~m}^{2} \mathrm{~s}^{-1}$ for $i=0$ and 1 . The most drastic change in surface salinity occurs when these two factors operate in the same direction; for example, under persistent westerlies and intense runoff: if $R\left[q y_{t-i}\right]=-0 \cdot 8 \mathrm{~m}^{2} \mathrm{~s}^{-1}$ for $i=0$ and 1 , and $R\left[Q r_{t-i}\right]=17 \mathrm{~m}^{3} \mathrm{~s}^{-1}$ for $i=0$, then $\Delta S s_{t} \sim-1 \cdot 6$, approximately the value of the standard deviation of the $R\left[S s_{t}\right]$ time series. Thus, at a fortnightly time scale, the deseasonalized and detrended surface salinity values 
are mainly controlled by the seasonal anomalies of runoff in the present fortnight, and by the cross-shore wind regime in the present and in the preceding fortnight period.

Once the seasonal component and the trend have been removed from the bottom salinity time series, the model that best fitted the resultant series, $R\left[S b_{t}\right]$, incorporates both components of the wind as explanatory variables i.e. both components of the Ekman transport, the deseasonalized along-shore, $R\left[q y_{t}\right]$, and cross-shore, $R\left[q x_{t}\right]$, Ekman transport time series (Table 4). $R\left[q y_{t}\right]$, which is associated with runoff, acts as a dilution as well as a dynamic factor; a value of $R\left[q y_{t}\right]=-0.8 \mathrm{~m}^{2} \mathrm{~s}^{-1}$, assuming that $R\left[q x_{t-i}\right]=0$ for $\mathrm{i}=0$ and 1 , involves a fall of $\Delta S b_{t} \sim-0.08$. Comparatively, the influence of cross-shore winds (or indistinctly, runoff) in the salinity values of the bottom layer is about $10 \%$ of that in the surface, this factor being the percentage of mixing between the surface and the bottom layers, and close to that calculated by following a different approach.

The influence of deseasonalized values of the crossshore Ekman transport, $R\left[q x_{t}\right]$ in bottom salinity $R\left[S b_{t}\right]$, can be considered as a non-local effect of wind conditions. Negative fortnightly averaged values of the seasonal anomaly of along-shore winds, $R\left[q x_{t}\right]$, are mainly related with high values of northerly winds in the averaging period. Northerly winds cause the upwelling of subsurface Eastern North Atlantic Central Water (ENAW) inside the Ría (Fraga, 1981), and also tend to increase the residual flows into the estuary (Prego \& Fraga, 1992; Alvarez-Salgado et al., 1993; Rosón et al., 1997). On one hand, we must consider that: (1) the upper limit of ENAW corresponds with the higher salinity values of the sub-surface water that upwells (Figure 9, line II); and (2) the higher the volume of shelf surface water transported seaward by northerly winds, the deeper the upwelled subsurface water that crosses the shelf and enters into the Ría (Castro et al., 1994). On the other hand, since upwelling enhances residual flows, strong and/or persistently nothernly winds tend to increase mixing between surface and bottom layers. Therefore, the effect of $R\left[q x_{t}\right]$ over bottom salinity is related to the haline properties of the upwelled water and to the influence of upwelling in the estuarine circulation pattern, which explains the complex weight function of the $R\left[q x_{t}\right]$ input variable in the TF model for $R\left[S b_{t}\right]$. By contrast, persistently anomalous high southerly winds $\left(R\left[q x_{t-i}\right]>0\right.$ for $\left.i \geq 0\right)$ have the contrary effect, since 
southernmost surface oceanic water (saltier) is advected northward, and by means of downwelling, affects the bottom layer of the Ría. In order to clarify the effect of upwelling in $R\left[S b_{t}\right]$, the authors have recoursed to the step response function. Let one suppose that $R\left[q y_{t}\right]=0 \mathrm{~m}^{2} \mathrm{~s}^{-1}$ and $R\left[q x_{t-i}\right]=-0.5 \mathrm{~m}^{2} \mathrm{~s}^{-1}$ (Table 1) for $i=0$ and $R\left[q x_{t-i}\right]=0 \mathrm{~m}^{2} \mathrm{~s}^{-1}$ for $i \geq 1$, then $\left.\Delta S b_{t}\right]=\sim 0.05$; but if persistent upwelling conditions occur, say $R\left[q x_{t-I}=-0.5 \mathrm{~m}^{2} \mathrm{~s}^{-1}\right.$ for $i=0$ and 1 , then $R\left[S b_{t}\right]$ rises weakly and $\Delta\left[S b_{t}\right]=\sim-0 \cdot 01$. In the first case, it is the upper limit of ENAW that reaches the bottom layer of the Ría. In the second case, the persistence of anomalous high upwelling conditions provoked not only the entrance of subsurface ENAW from below the upper limit of ENAW, but also intense mixing between surface and bottom layers into the Ría. The most drastic change in $R\left[S b_{t}\right]$ occurs when the components of the wind work in the same direction, in the present fortnightly period; if $R\left[q x_{t-i}=-0.5\right.$ and $R\left[q y_{t-i}=0 \cdot 8\right.$, both for $i=0$ (i.e. north-easterlies), $\Delta\left[S b_{t}\right]=\sim 0 \cdot 13$.

Surface and bottom temperature $\left(\mathrm{R}\left[\mathrm{ts}_{\mathrm{t}}\right]\right.$ and $\left.\mathrm{R}\left[\mathrm{tb}_{\mathrm{t}}\right]\right)$

Due to the inertial behaviour of temperature, the univariate models, both for surface and bottom temperature, explained a significant amount of variance, 24 and $50 \%$, respectively (Tables 5 and 6). Present fortnightly values of the deseasonalized and detrended surface temperature, $R\left[t s_{t}\right]$, depended on the values of the immediately preceding fortnight, while bottom temperature time series, $R\left[t b_{t}\right]$, could be specified by a second-order autoregressive process which explains an important percentage of variance of this time series. The difference between the structure of the autoregressive processes that generated the temperature series is due to the inertial behaviour of bottom temperature, stronger than that for surface temperature. This fact to related with the long residence time of water in the bottom layer.

Surface and bottom temperature time series have been best described by means of TF models. In both cases, the main factor which controls temperature evolution is the seasonal anomaly of the cross-shore Ekman transport, $R\left[q x_{t}\right]$, and the respective transfer functions show similar structure; present fortnightly values of the output variable depend on present and immediately preceding fortnightly values of the input one. Therefore, present values of 
temperature depend on the along-shore wind regime over the adjacent shelf (a non-local effect of wind) within a time scale between 15 and 30 days. However, the structure of the transfer functions showed an interesting distinctive feature: the dependence on immediately preceding fortnightly values of the input variable is more pronounced for the bottom series than for the surface series. This fact is related with the estuarine circulation and with the strong coupling between the shelf and the Ría (Fraga, 1981; Blanton et al., 1987), since the bottom layer is more sensitive to shelf processes than the surface layer. Besides, the estimated lag structure of the transfer functions is in accordance with the mean residence time computed for the Ría de Vigo.

The step response function was used to quantify the effect of cross-shore Ekman transport on temperature series, and to compare this effect on the bottom and surface series. For instance, if $R\left[q x_{t-i}\right]=-0.5 \mathrm{~m}^{2} \mathrm{~s}^{-1}$ for $i=0$ and 1 (i.e. persistent anomalous upwelling conditions), there would be a drop in temperature of $\Delta\left[t s_{t}\right]=\sim-0.60{ }^{\circ} \mathrm{C}$ for surface series and $\Delta\left[t b_{t}\right]=\sim-0.55{ }^{\circ} \mathrm{C}$ for bottom series. In order to compare these results, they can be normalized by quoting them as a percentage of change relative to the respective standard deviation of the fortnightly averaged temperature series (Table 1). Thus, the above proposal situation involves a drop of temperature of $\sim 29$ and $\sim 55 \%$ of the value of the standard deviation for the surface and bottom series, respectively. Let one suppose now that $R\left[q x_{t-}\right.$ $\left.{ }_{i}\right]=0.5 \mathrm{~m}^{2} \mathrm{~s}^{-1}$ for $i=0$, and $=-0.5 \mathrm{~m}^{2} \mathrm{~s}^{-1}$ for $i=1$ (i.e. present anomalous southerly winds preceding by anomalous northerly winds: an upwelling-downwelling cycle), considering the transfer functions alone, there would be a drop in the fortnightly averaged surface temperature, $\Delta\left[t s_{t}\right]=\sim-0.10^{\circ} \mathrm{C}$, while, due to the major influence on the preceding fortnightly conditions, $\Delta\left[t b_{t}\right]=\approx-0.25^{\circ} \mathrm{C}$ in the present fortnightly average value of the bottom layer. These values represent a change of 5 and $25 \%$ of the value of the standard deviation for the surface and bottom temperature series, respectively. These different results are related to the volumetric ratio between the surface and the bottom layer, which determines the residence time of water in this layer being longer than that for the surface layer, thus explaining its major inertia. 
Another difference that could be observed between the TF models built for surface and bottom temperature time series is that, for this last series, $R\left[t b_{t}\right]$, the model incorporates the effect of anomalous crossshore winds, $R\left[q y_{t}\right]$, as the explanatory variable (Table 6). However, the percentage of explained variance gained when this input variable is introduced into the model was very low. A possible explanation would be related to the local effect of cross-shore wind conditions, which influences the mixing between surface and bottom layers.

\section{Evaluation of model performance}

In order to demonstrate the advantage of TF models against standard multiple regression models to describe the dynamic behaviour of the ecosystem, their theoretical forecasting performance should be compared. This assessment, where possible, should be performed against data not used for model building. In the present case, meteorological values monitored in the year 1993 have been used. The data which validate the model output are thermohaline properties measured in 1993 at the hydrographic station (Stn E3) (Figure 1). Both input and validation data were managed as described in the text, to obtain fortnightly averaged values.

The forecasting capability was measured by means of the coefficient of determination $\left(r^{2}\right)$ between the model output and the validation data (Table 7). In all cases, TF models explain a higher percentage of variance than the multiple regression models. This fact is clearly shown in Figure 10, where measured and fortnightly averaged thermohaline properties for 1993 were plotted against the outputs from the TF model and for the standard regression model. In all cases, the best fit against the validation data was obtained with the TF models.

There are two reasons why the TF model is more suitable than the multiple regression model to describe the dynamic behaviour of the ecosystem: (1) the structure of the transfer function, which allows the inclusion of lagged explanatory variables as input; and (2) the autocorrelation function, the noise term $\left(N_{t}\right)$, which incorporates the effect of other relevant 
input variables not implicitly included in the model. To illustrate these points, the results from the validation test (Table 7 and Figure 10) shall be referred to.

The most noticeable differences between the output from the multiple regression and TF models were obtained for the seasonal anomalies of surface temperature, $R\left(\left[t s_{t}\right]\right.$ [upper graph of Figure 10(c)], and for bottom temperature [Figure 10(d)]. In the first case, the

differences sharpen from July to September; both models failed to pick up the drastic drop in surface temperature which occurred at the end of June 1993, but, whereas the multiple regression model continued to fail during the summer months, the TF model reproduced the summer evolution of the seasonal anomalies of surface temperature fairly well. Due to the considerable amount of variance explained by the seasonal cycle of surface temperature (foot of Table 5) the difference between the two types of models is low when the seasonal (deterministic) component is added to the seasonal anomalies. The situation is similar for bottom temperature, although, in this case, the differences between the two types of models remain when the seasonal component is added to the seasonal anomalies, due to the relatively low amount of variance retained by this deterministic component (foot of Table 6). Thus, TF models are better than multiple regression models since they allow one to incorporate lagged relationships (e.g. the effect of the persistence of forcing) and other related variables not implicitly included as explanatory variables (e.g. changes in the thermohaline properties of the upwelled water).

\section{Conclusions}

The TF models built to describe the thermohaline behaviour produce better fit than the multiple regression models; the former had a lower residual variance and a higher percentage of explained variance than the latter. This affirmation stands out when both types of models are subjected to a simulation test performed against data not used for model building.

The TF models are useful tools to describe the behaviour of ecosystems which are sensitive to the persistance of the forcing factors and/or when it is not possible to include some 
explanatory variables in the model formation. In this respect, they are usable for ecosystem management purposes.

Finally, in order to improve the built TF models, it is necessary to: (1) enable higher variability to be transferred from the meteorological forcing to the temporal development of the thermohaline properties by means of a finer definition of the input variables (e.g. local wind conditions) and (2) allow the model to incorporate the small effect of the time variant and non-linearity of the input-output relationships.

\section{Acknowledgements}

Support for this work came from CICYT Project AMB 92-0165. The authors thank the Instituto Español de Oceanografía (I.E.O.) in Vigo, which supplied the upwelling indices, and the Instituto Nacional de Meteorología (I.N.M.) in A Coruña, which supplied the meteorological variables. Particularly the authors also thank: Dr F. Fraga, who had the idea of continuous monitoring of the hydrographic conditions in the Ría de Vigo; Ricardo Casal, skipper of the Lampadena; and all the members of the Oceanographic Group of the Instituto de Investigacións Mariñas (I.I.M). E. Nogueira was supported by a fellowship from the MORENA Project (CEE. MAST II PL-920092-D). The authors also gratefully acknowledge the valuable comments provided by the referee, R. G. Wood.

\section{References}

Alvarez-Salgado, X.A., Rosón, G., Pérez, F.F., \& Pazos, Y. 1993 Hydrographic variability off the Rías Baixas (NW Spain) Turing the upwelling season. Journal of Geophysical Research 98, 14447-14455.

Bakun, A. 1973 Coastal Upwelling Indices, West Coast of North America, 1946-71, NOAA, Technical Reports, NMFSSSRF-671, 103 pp.

Beer, T. 1983 Environmental Oceanography. Pergamon Press, Oxford, 262 pp. 
Blanton, J. O., Tenore, K. R., Castillejo, F., Atkinson, L. P., Schwing, F. B. \& Lavín, A. 1987 The relationship of upwelling to mussel production in the rías on the Western Coast of Spain. Journal of Marine Research 45, 497-511.

Box, G. E. P. \& Jenkins, G. M. 1976 Time Series Analysis, Forecasting and Control. Holden-Day, San Francisco.

Castro, C. G., Pérez, F. F., Alvarez-Salgado, X. A., Rosón, G. \& Ríos, A. F. 1994 Hydrographic conditions associated with the relaxation of an upwelling event off the Galician coast (NW Spain). Journal of Geophysical Research 99, 5135-5147.

Chase, J. 1975 Wind-driven circulation in a Spanish estuary, Estuarine and Coastal Marine Science 3, 303-310.

Chatfield, C. 1992 The Analysis of Time Series, an Introduction $4^{\text {th }}$ Edition. Chapman \& Hall, New York, 131 pp.

Dietrich, G., Kalle, K., Krauss, W. \& Siedler, G. 1980 General Oceanography. An Introduction 2nd Edition. J. Wiley \& Sons, $626 \mathrm{pp}$.

Figueiras, F. G., Jones, K. J., Mosquera, A. M., Alvarez- Salgado, X. A., Edwards, A. \& MacDougall, N. 1994 Red tide assemblage formation in an estuarine upwelling ecosystem: Ría de Vigo. Journal of Plankton Research 16, 857-878.

Fraga, F. 1981 Upwelling oV the Galician coast, Northwest Spain. In Coastal and Estuarine Sciences 1. Coastal Upwelling (Richards, F. A., ed.). American Geophysical Union, Washington DC, pp. 176-182.

Goldman, R. Ch., Jassby, A. \& Powell, T. 1989 Interannual fluctuations in primary production: meteorological forcing at two subalpine lakes. Limnology and Oceanography 34, 310-323.

Hirsch, R. M., Slack, J. R. \&. Smith, R. A. 1982 Techniques of trend analysis for monthly water quality data. Water Resources Research 18, 107-121.

Jassby, A. D. \& Powell, T. M. 1990 Detecting changes in ecological time series. Ecology 71, 2044-2052.

Jenkins, G. M. 1979 Practical Experiences with Modelling and Forecasting Time Series. Gwilym Jenkins and Partners (Overseas) Ltd. Jersey, 146 pp. 
Jordan, T. E., Correll, D. L., Miklas, J. \& Weller, D. E. 1991 Long-term trends in estuarine nutrients and chlorophyll, and short-term eVects of variation in watershed discharge. Marine Ecology Progress Series 75, 121-132.

Keller, A. 1987 Modeling and forecasting primary production rates using Box-Jenkins transfer function models. Canadian Journal of Fishery and Aquatic Sciences 44, 10451052.

Legendre, L. \& Legendre, P. 1983 Numerical Ecology. Elsevier, Amsterdam.

Lenhart, H. J., Radach, G., Backhaus, J. O. \& Pohlmann, T. 1995 Simulations of the North Sea circulation, its variability, and its implementation as hidrodinamical forcing in ERSEM. Netherlands Journal of Sea Research 33, 271-299.

Lewis, M. R. \& Platt, T. 1982 Scales of variability in estuarine ecosystems. In Estuarine Comparisons (Kenedy, V. S., ed.). Academic Press, New York, pp. 3-20.

McClain, C. R., Shenn-Yu Chao, Atkinson, L. P., Blanton, J. O. \& Castillejo, F. 1986 Wind driven upwelling in the vicinity of Cape Finisterre, Spain, Journal of Geophysical Research 91, 8470-8486.

Mendelssohn, R. 1981 Using Box-Jenkins models to forecast fishery dynamics: identification, estimation and checking. Fishery Bulletin 78, 887-896.

Nogueira, E., Pérez, F. F. \& Ríos, A. F. 1997 Seasonal patterns and long-term trends in an estuarine upwelling ecosystem (Ría de Vigo, NW Spain). Estuarine, Coastal and Shelf Science 44, 285-300.

Peña, D. \& Arnáiz, G. 1981 Criterios de selección de modelos ARIMA. Trabajos $d$ Estadística y de Investigación Operativa 1, 70-93.

Peña, D. 1992 Estadística Modelos y Métodos. 2. Modelos Lineales y Series Temporales. Alianza Editorial, Madrid, 743 pp.

Pilson, M. E. Q. 1985 Annual cycles of nutrients and chlorophyll in Narragansett Bay, Rhode Island. Journal of Marine Research 43, 849-873.

Pond S. \& Pickard, G. L. 1986 Introductory Dynamical Oceanography 2nd edition. Pergamon Press, Oxford, 329 pp.

Poole, R. W. 1976 Empirical multivariate autoregressive equation predictors of the fluctuations of interacting species. Mathematical Biosciences 28, 81-97. 
Prego, R. \& Fraga, F. 1992 A simple model to calculate the residual flows in a Spanish Ria. Hydrographic consequences in the Ría of Vigo. Estuarine, Coastal and Shelf Science 34, 603-615.

Ríos, A. F. 1992 El Fitoplancton en la Rl'a de Vigo y sus Condiciones Ambientales. Ph.D., University of Santiago, $416 \mathrm{pp}$.

Ríos, A. F., Nombela, M. A., Pérez, F. F., Rosón, G. \& Fraga, F. 1992 Calculation of runoff to an estuary. Ría de Vigo. Scientia Marina 56, 29-33.

Rosón, G., Pérez, F. F., Alvarez-Salgado, X. A. \& Figueiras, F. G. 1995 Variation of both thermohaline and chemical properties in an estuarine upwelling ecosystem: Ría de Arousa. I. Time evolution. Estuarine, Coastal and Shelf Science 41, 195-213.

Rosón, G., Alvarez-Salgado, X. A \& Pérez, F. F. 1997 A nonstationary box model to determine residual fluxes in a partially mixed estuary, based on both thermohaline properties. Application to the R1'a de Arousa (NW Spain). Estuarine, Coastal and Shelf Science 44, 249-262.

Schindler, D. W. 1987 Detecting ecosystem responses to anthropogenic stress. Canadian Journal of Fishery and Aquatic Sciences 44 (Suppl. 1), 6-25.

Taylor, C. D. \& Howes, B. L. 1994 Effect of sampling frequency on measurements of seasonal primary production and oxygen status in near-shore coastal ecosystems. Marine Ecology Progress Series 108, 193-203.

Tiao, G. C. \& Box, G. E. P. 1981 Modeling multiple time series with applications. Journal of the American Statistical Association 76, 802-816.

UNESCO 1983 Algorithms for Computation of Fundamental Properties of Seawater. UNESCO Technical Papers in Marine Science 44, 53 pp.

van Belle, G. \& Hughes, J. P. 1984 Nonparametric tests for trend in water quality, Water Resources Research 20, 127-136. 
Table 1. Standard deviation of the rough time series and the reduction of variance due to the data handling. The mean and the standard deviation of the fortnightly averaged time series are also shown (sfc., surface; btm, bottom)

\begin{tabular}{|c|c|c|c|c|c|c|c|}
\hline \multirow{2}{*}{$\begin{array}{l}\text { Variables } \\
\end{array}$} & \multicolumn{2}{|c|}{ Rough } & \multirow{2}{*}{$\begin{array}{l}\rightarrow \text { Purged and filled } \\
n=626 \\
\% \text { var }=100 \\
\text { SD }\end{array}$} & \multirow{2}{*}{$\begin{array}{l}\rightarrow \text { Low-pass } \\
\text { filtered } \\
\text { \% var }\end{array}$} & \multicolumn{3}{|c|}{$\begin{array}{l}\text { Fortnightly } \\
\text { averaged }\end{array}$} \\
\hline & SD & $n$ & & & $\begin{array}{l}\% \\
\text { var }\end{array}$ & Mean & SD \\
\hline \multicolumn{8}{|l|}{ Meteorological } \\
\hline $\begin{array}{l}\text { Cross-shore Ekman transport, } \\
q x\left(\mathrm{~m}^{2} \mathrm{~s}^{-1}\right)\end{array}$ & $0 \cdot 89$ & 626 & - & 41 & 31 & $0 \cdot 06$ & $0 \cdot 49$ \\
\hline $\begin{array}{l}\text { Along-shore Ekman transport, } \\
\text { qy }\left(\mathrm{m}^{2} \mathrm{~s}^{-1}\right)\end{array}$ & $1 \cdot 37$ & 626 & - & 45 & 33 & $-0 \cdot 21$ & $0 \cdot 80$ \\
\hline $\begin{array}{l}\text { Runoff in the drainage basin up to } \\
\text { Stn E3, } Q r\left(\mathrm{~m}^{3} \mathrm{~s}^{-1}\right)\end{array}$ & $21 \cdot 8$ & 626 & - & 71 & 59 & $20 \cdot 5$ & $16 \cdot 8$ \\
\hline 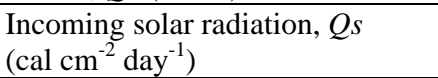 & 166 & 626 & - & 87 & 83 & 416 & 152 \\
\hline \multicolumn{8}{|l|}{ Thermohaline } \\
\hline \multicolumn{8}{|l|}{ Salinity } \\
\hline sfc. & $2 \cdot 09$ & 545 & $2 \cdot 14$ & 75 & 653 & $4 \cdot 26$ & $1 \cdot 72$ \\
\hline btm. & $0 \cdot 28$ & 540 & $0 \cdot 28$ & 67 & 55 & $35 \cdot 57$ & $0 \cdot 20$ \\
\hline \multicolumn{8}{|l|}{ Temperature $\left({ }^{\circ} \mathrm{C}\right)$} \\
\hline sfc. & $2 \cdot 28$ & 542 & $2 \cdot 26$ & 93 & 90 & $15 \cdot 21$ & $2 \cdot 14$ \\
\hline btm. & $1 \cdot 12$ & 540 & $1 \cdot 13$ & 92 & 85 & $13 \cdot 65$ & $1 \cdot 04$ \\
\hline
\end{tabular}

sfc, surface; btm, bottom.

Table 2. Pearson correlation coefficient between deseasonalized meteorological variables $(r=0 \cdot 16, P<0 \cdot 05)$ and loads of the deseasonalized meteorological variables with the principal components (PCs) derived from the PC analysis with the percentage of variance $(\% \mathrm{EV})$ retained by each component

\begin{tabular}{|l|l|l|l|l|l|l|l|l|}
\hline \multicolumn{2}{|l}{ Pearson correlation } & Variable & \multicolumn{4}{|l|}{ Principal component } \\
\cline { 6 - 10 } \multicolumn{2}{|l|}{} & & PC1 & PC2 & PC3 & PC4 \\
\hline Rqx & Rqy & RQr & RQs & & & & & \\
\hline $1 \cdot 00$ & & & & Rqx & $0 \cdot 36$ & $0 \cdot 90$ & $0 \cdot 24$ & $-0 \cdot 02$ \\
\hline$-0 \cdot 18$ & $1 \cdot 00$ & & & Rqy & $-0 \cdot 85$ & $0 \cdot 07$ & $0 \cdot 54$ & $-0 \cdot 46$ \\
\hline $0 \cdot 16$ & $-0 \cdot 60$ & $1 \cdot 00$ & & $R Q r$ & $0 \cdot 82$ & $-0 \cdot 06$ & $-0 \cdot 37$ & $-0 \cdot 42$ \\
\hline$-0 \cdot 06$ & $0 \cdot 34$ & $-0 \cdot 28$ & $1 \cdot 00$ & RQs & $-0 \cdot 61$ & $0 \cdot 37$ & $-0 \cdot 70$ & $0 \cdot 06$ \\
\hline & & & & $\%$ EV & $47 \cdot 4$ & $23 \cdot 8$ & $18 \cdot 8$ & $10 \cdot 0$ \\
\hline & & & & Cumulative \% EV & $47 \cdot 4$ & $71 \cdot 3$ & $90 \cdot 1$ & $100 \cdot 0$ \\
\hline
\end{tabular}

Table 3. Multiple regression (m. reg.), univariate autoregressive (AR) and single input and multiple input transfer function (TF) models relating deseasonalized and detrended surface salinity (RSs) to meteorological variables (v) and to their derived principal components (PCs)

\begin{tabular}{|l|l|l|l|l|l|}
\hline $\begin{array}{l}\text { Model } \\
\text { type }\end{array}$ & & Fitted model & & Residual & $R S s+\mathrm{SSC}+\mathrm{T}$ \\
\cline { 3 - 6 } & & & $r^{2}$ & variance \\
\cline { 3 - 6 } m. reg. (v) & & $R S s=0 \cdot 8 R q y-0 \cdot 037 R Q r$ & $0 \cdot 48$ & $1 \cdot 102$ & $0 \cdot 63$ \\
\hline m. reg. (PC) & & $R S s=-0 \cdot 96 \mathrm{PC} 1+0 \cdot 32 \mathrm{PC} 3$ & $0 \cdot 48$ & $1 \cdot 099$ & $0 \cdot 63$ \\
\hline AR & & $R S s_{t}=0 \cdot 35 B S s_{t}$ & $0 \cdot 12$ & $1 \cdot 867$ & $0 \cdot 37$ \\
\hline TF(v) & Single input: $R q y$ & $R S s_{t}=(1 \cdot 1+0 \cdot 7 B) R q y_{t}+0 \cdot 20 B N_{t}$ & $0 \cdot 54$ & $0 \cdot 994$ & $0 \cdot 67$ \\
\hline & Single input: $R Q r$ & $R S s_{t}=-0 \cdot 060 R Q r_{t}+0 \cdot 28 B N_{t}$ & $0 \cdot 43$ & $1 \cdot 201$ & $0 \cdot 59$ \\
\hline & Multiple input: $R q y$ \& $R Q r(\rightarrow)$ & $\begin{array}{l}R S s_{t}=(1 \cdot 1+0 \cdot 7 B) R q y_{t}-0 \cdot 031 \\
\left(R Q r_{t}+(12+3 B) R q y_{t}\right\}+0 \cdot 21 B A_{t}\end{array}$ & $0 \cdot 60$ & $0 \cdot 852$ & $0 \cdot 71$ \\
\hline TF(PC) & Single input: PC1 & $\begin{array}{l}R S s_{t}=-(0 \cdot 88+0 \cdot 46 B) P C 1_{t} \\
+0 \cdot 22 B N_{t}\end{array}$ & $0 \cdot 56$ & $0 \cdot 943$ & $0 \cdot 68$ \\
\hline & Single input: PC3 & $R S s_{t}=0 \cdot 3 P C 3_{t}+0 \cdot 35 B N_{t}$ & $0 \cdot 17$ & $1 \cdot 765$ & $0 \cdot 40$ \\
\hline & Multiple input: PC1 \& PC3 & $\begin{array}{l}R S s_{t}=-(0 \cdot 89+0 \cdot 44 B) \\
P C 1_{t}+0 \cdot 3 P C 3 t+0 \cdot 23 B N_{t}\end{array}$ & $0 \cdot 60$ & $0 \cdot 856$ & $0 \cdot 71$ \\
\hline
\end{tabular}

Total variance (deterministic components): $\mathrm{SSC}=0 \cdot 631 ; \mathrm{T}=0 \cdot 123$; (random component): $R S s=2 \cdot 122$. 
Table 4. Multiple regression (m. reg.), univariate autoregressive (AR) and single input and multiple input transfer function (TF) models relating deseasonalized and detrended bottom salinity (RSb) to meteorological variables (v) and to their derived principal components (PCs)

\begin{tabular}{|c|c|c|c|c|c|}
\hline \multirow[t]{2}{*}{$\begin{array}{l}\text { Model } \\
\text { type }\end{array}$} & & \multirow[t]{2}{*}{ Fitted model } & & \multirow[t]{2}{*}{$\begin{array}{l}\text { Residual } \\
\text { variance }\end{array}$} & $\begin{array}{l}R S b \\
+\mathrm{SSC}+\mathrm{T}\end{array}$ \\
\hline & & & $r^{2}$ & & $r^{2}$ \\
\hline m. reg. (v) & & $R S s=-0 \cdot 9 R q y+0 \cdot 010 R Q y$ & $0 \cdot 26$ & $0 \cdot 019$ & $0 \cdot 53$ \\
\hline m. reg. (PC) & & $R S s=-0 \cdot 09 \mathrm{PC} 1$ & $0 \cdot 28$ & 0.019 & 0.55 \\
\hline AR & & $R S b_{t}=\left(0 \cdot 32 B-0 \cdot 30 B^{23}\right) R S b_{t}$ & $0 \cdot 16$ & $0 \cdot 822$ & $0 \cdot 46$ \\
\hline \multirow[t]{3}{*}{$\mathrm{TF}(\mathrm{v})$} & Single input: Rqy & $\begin{array}{l}R S b_{t}=-(0 \cdot 14+0 \cdot 10 B) R q x_{t}+(0 \cdot 33 B- \\
\left.0 \cdot 26 B^{23}\right) N_{t}\end{array}$ & $0 \cdot 26$ & $0 \cdot 020$ & $0 \cdot 52$ \\
\hline & Single input: $R Q r$ & $R S b_{t}=0 \cdot 11 R q y_{t}+\left(0 \cdot 40 B-0 \cdot 19 B^{23}\right) N_{t}$ & $0 \cdot 43$ & $0 \cdot 017$ & $0 \cdot 58$ \\
\hline & $\begin{array}{l}\text { Multiple input: } \\
\text { Rqy \& } \operatorname{RQr}(\rightarrow)\end{array}$ & $\begin{array}{l}R S b_{t}=-(0 \cdot 10-0 \cdot 08 B) R q x_{t} \\
+0 \cdot 10 R q y_{t}+\left(0 \cdot 39 B-0 \cdot 19 B^{23}\right) N_{t}\end{array}$ & $0 \cdot 41$ & $0 \cdot 016$ & $0 \cdot 62$ \\
\hline \multirow[t]{3}{*}{$\mathrm{TF}(\mathrm{PC})$} & Single input: PC2 & $R S b_{t}=-0 \cdot 0 \cdot 4 B P C 2_{t}+\left(0 \cdot 41 B-0 \cdot 14 B^{23}\right) N_{t}$ & $0 \cdot 22$ & $0 \cdot 021$ & $0 \cdot 49$ \\
\hline & Single input: PC1 & $R S b_{t}=0 \cdot 09 \mathrm{PC} 1_{\mathrm{t}}+\left(0 \cdot 30 B-0 \cdot 29 B^{23}\right) N_{t}$ & $0 \cdot 39$ & $0 \cdot 016$ & $0 \cdot 61$ \\
\hline & $\begin{array}{l}\text { Multiple input: } \\
\text { PC1 \& PC2 }\end{array}$ & $\begin{array}{l}R S b_{t}=-0 \cdot 03 B P C 2_{\mathrm{t}}-0 \cdot 08 \mathrm{PC} 1_{\mathrm{t}}+(0 \cdot 40 B- \\
\left.0 \cdot 15 B^{23}\right) N_{t}\end{array}$ & $0 \cdot 49$ & $0 \cdot 016$ & $0 \cdot 62$ \\
\hline
\end{tabular}

Total variance (deterministic components): $\mathrm{SSC}=0 \cdot 0091 ; \mathrm{T}=0 \cdot 0066$; (random component): $R S b=0 \cdot 0264$.

Table 5. Multiple regression (m. reg.), univariate autoregressive (AR) and single input transfer function (TF) models relating deseasonalized and detrended surface temperature (Rts) to meteorological variables $(\mathrm{v})$ and to their derived principal components (PCs)

\begin{tabular}{|c|c|c|c|c|c|}
\hline $\begin{array}{l}\text { Model } \\
\text { type }\end{array}$ & & Fitted model & $r^{2}$ & $\begin{array}{l}\text { Residual } \\
\text { variance }\end{array}$ & $\begin{array}{l}\text { Rts }+\mathrm{SSC}+\mathrm{T} \\
r^{2}\end{array}$ \\
\hline m. reg. (v) & & $R t s=0 \cdot 6 R q x$ & $0 \cdot 04$ & $0 \cdot 834$ & $0 \cdot 82$ \\
\hline m. reg. (PC) & & Rts $=0 \cdot 16 \mathrm{PC} 2$ & 0.03 & 0.846 & $0 \cdot 82$ \\
\hline AR & & Rts $_{t} 0 \cdot 49 B R t s_{t}$ & $0 \cdot 24$ & $0 \cdot 668$ & $0 \cdot 8$ \\
\hline $\mathrm{TF}(\mathrm{v})$ & Single input: $R q x(\rightarrow)$ & $R t s_{t}=(0 \cdot 5+0 \cdot 7 B) R q x_{t}-0 \cdot 47 B N_{t}$ & $0 \cdot 31$ & $0 \cdot 607$ & $0 \cdot 87$ \\
\hline $\mathrm{TF}(\mathrm{PC})$ & Single input: PC2 & $R t s_{t}=0 \cdot 16 P C 2_{t}+0 \cdot 48 B N_{t}$ & $0 \cdot 25$ & $0 \cdot 657$ & $0 \cdot 86$ \\
\hline & Single input: PC1 & $R t s_{t}=0 \cdot 21 B P C 1_{t}+0 \cdot 47 B N_{t}$ & $0 \cdot 26$ & 0.647 & $0 \cdot 86$ \\
\hline & Multiple input: PC1 \& PC2 & $R t s_{t}=0 \cdot 20 B P C 1_{t}+0 \cdot 14 \mathrm{PC}_{\mathrm{t}}+0 \cdot 46 B N_{t}$ & $0 \cdot 29$ & $0 \cdot 617$ & $0 \cdot 86$ \\
\hline
\end{tabular}

Total variance (deterministic component): SSC=3·616; $\mathrm{T}=0 \cdot 021$; (random component): $R t s=0 \cdot 872$.

Table 6. Multiple regression (m. reg.), univariate autoregressive (AR) and single input and multiple input transfer function (TF) models relating deseasonalized and detrended bottom temperature (Rtb) to meteorological variables (v) and to their derived principal components (PCs)

\begin{tabular}{|c|c|c|c|c|c|}
\hline \multirow{2}{*}{$\begin{array}{l}\text { Model } \\
\text { type }\end{array}$} & & \multirow[t]{2}{*}{ Fitted model } & & \multirow{2}{*}{$\begin{array}{l}\text { Residu } \\
\text { al } \\
\text { varian } \\
\text { ce }\end{array}$} & $R t b+\mathrm{SSC}+\mathrm{T}$ \\
\hline & & & $r^{2}$ & & $r^{2}$ \\
\hline m. reg. (v) & & $R t b=0 \cdot 5 R q x$ & 0.06 & $0 \cdot 512$ & $0 \cdot 53$ \\
\hline m. reg. (PC) & & $R t b=0 \cdot 25 \mathrm{PC} 1$ & $0 \cdot 11$ & $0 \cdot 482$ & $0 \cdot 55$ \\
\hline AR & & $\left.R t b_{t}=\left(0 \cdot 86 B-0 \cdot 26 B^{2}\right) R t b_{t}\right)$ & $0 \cdot 50$ & $0 \cdot 269$ & $0 \cdot 75$ \\
\hline \multirow[t]{3}{*}{$\mathrm{TF}(\mathrm{v})$} & Single input: $R q x$ & $\begin{array}{l}R t b_{t}=(0 \cdot 4+0 \cdot 8 B) R q x_{t}+ \\
\left(0 \cdot 74 B-0 \cdot 22 B^{2}\right) N_{t}\end{array}$ & $0 \cdot 52$ & $0 \cdot 257$ & $0 \cdot 77$ \\
\hline & Single input: Rqy & $\left.R t b_{t}=-0 \cdot 27 R q y t+\left(0 \cdot 76 B-0 \cdot 18 B^{2}\right) N_{t}\right)$ & $0 \cdot 47$ & $0 \cdot 287$ & $0 \cdot 74$ \\
\hline & Multiple input: $R q x \&$ Rqy $(\rightarrow)$ & $\begin{array}{l}R t b_{t}=(0 \cdot 3+0 \cdot 8 B) \text { Rqx }_{t^{-}} \\
0 \cdot 26 R q y_{t}+\left(0 \cdot 69 B-0 \cdot 18 B^{2}\right) N_{t}\end{array}$ & $0 \cdot 54$ & $0 \cdot 252$ & $0 \cdot 77$ \\
\hline \multirow[t]{3}{*}{$\mathrm{TF}(\mathrm{PC})$} & Single input: PC2 & $R t b_{t}=0 \cdot 24 B P C 2_{t}+\left(0 \cdot 78 B-0 \cdot 22 B^{2}\right) N_{t}$ & $0 \cdot 49$ & $0 \cdot 277$ & $0 \cdot 75$ \\
\hline & Single input: PC1 & $R t b_{t}=0 \cdot 25 \mathrm{PC} 1 \mathrm{t}+0 \cdot 62 B N_{t}$ & $0 \cdot 46$ & $0 \cdot 292$ & $0 \cdot 73$ \\
\hline & Multiple input: PC2 \& PC1 & $\begin{array}{l}R t b_{t}=(0 \cdot 06+0 \cdot 28 B) \mathrm{PC}_{\mathrm{t}}+ \\
0 \cdot 29 \mathrm{PC} 1_{\mathrm{t}}+0 \cdot 57 B N_{t}\end{array}$ & $0 \cdot 50$ & $0 \cdot 271$ & $0 \cdot 75$ \\
\hline
\end{tabular}

Total variance (deterministic component): SSC=0·485; T=0.042; (random component): $R t b=0 \cdot 543$. 
Table 7. Coefficient of determination $(r 2)$ between fortnightly averaged thermohaline properties and the output of the multiple regression (m. reg.) and transfer function (TF) models, for 1993

\begin{tabular}{|l|l|l|l|l|l|}
\hline & Model type & $R[S s]$ & $R[S s]+$ SSC & $R[t s]$ & $R[t s]+$ SSC \\
\hline sfc. & m. reg. & $0 \cdot 60$ & $0 \cdot 53$ & $0 \cdot 11$ & $0 \cdot 82$ \\
\hline & TF & $0 \cdot 73$ & $0 \cdot 69$ & $0 \cdot 52$ & $0 \cdot 90$ \\
\hline & & $R[S b]$ & $R[S b]+$ SSC & $R[t b]$ & $R[t b]+$ SSC \\
\hline btm & m. reg. & $0 \cdot 60$ & $0 \cdot 49$ & $0 \cdot 42$ & $0 \cdot 44$ \\
\hline & TF & $0 \cdot 64$ & $0 \cdot 55$ & $0 \cdot 66$ & $0 \cdot 74$ \\
\hline
\end{tabular}

